\title{
Lise ve Dengi Okullardaki Öğrencilerin Fast Food Tüketim Kararları
}

\author{
Emine İKİKAT TÜMER (D) \\ ${ }^{1}$ Kahramanmaraş Sütçü İmam Üniversitesi Ziraat Fakültesi Tarım Ekonomisi Bölümü, Kahramanmaraş \\ $\bigotimes:$ 2katumer@gmail.com
}

\begin{abstract}
ÖZET
Kadınların iş hayatına girmesi ve zamanının büyük bir bölümünü işte geçirmesi, aile gelirinin artması, büyük şehirlerdeki ulaşım problemi, fast food restoranların sayısındaki hızlı artış ve bu restoranların evlere servis yapması gibi faktörler nedeniyle kısa sürede hazırlanan ya da hazır tüketilen yiyecekler günümüz toplumlarında önem kazanmaktadır. Bu çalışmada lise ve dengi okullarda eğitim gören ögrencilerin fast food tüketim kararları ve bu kararlarını belirlemede etkili olan faktörlerin ortaya konulması amaçlanmıştır. Bu amaçla 2012 yılında Erzurum ilinde lise ve dengi okullarda öğrenim gören 126 öğrenci ile anket yapılmış ve elde edilen veriler Repertuar çizelgesi tekniği ile analiz edilmiştir. Öğrencilere gıdaların fiyatı, lezzeti, sağlıklı olması ve kısa sürede hazırlanması olmak üzere 4 kriter sunulmuştur. Öğrencilerin bu kriterler arasından tükettikleri gidaların lezzetli olmasına en fazla önemi verdikleri, daha sonra sırasıyla tükettikleri gıdaların sağlıklı olması, hazırlama süresi ve fiyatına önem verdikleri belirlenmiştir.
\end{abstract}

\section{DOI:10.18016/ksudobil.348267}

\author{
Makale Tarihçesi \\ Received : 04.03.2016 \\ Accepted : 28.06.2016
}
Anahtar Kelimeler
Öğrenci,
Fast food,
Tüketim,
Repertuar çizelgesi tekniği,
Tütkiye

\section{Araştırma Makalesi}

\section{Fast Food Consumption Decisions of High School and Equivalent School Students}

\begin{abstract}
In today's societies, ready-consumed foods or foods that are prepared in short time is gaining importance due to the factors including; increase in family income, transportation problem in metropolitan cities, increase in number of fast food restaurants and their delivery services, and increase women's part in business life and spending more time at work. Objective of this study was to determine the fast food consumption decisions of high school and equivalent school students and the factors effecting in making their decisions. Thus, 126 students attending high school or equivalent schools in Erzurum in 2012 were surveyed, and the data were obtained through the Repertory Grid Technique. Four criteria were presented to students including foods price, taste, healthiness and being prepared in short time. It was concluded that, among all criteria presented, students give importance the deliciousness of foods the most, and then healthiness, preparation time, and price of them, respectively.
\end{abstract}

\author{
Article History \\ Geliş : 04.03.2016 \\ Kabul : 28.06.2016
}

Keywords
Student,
Fast Food,
consumption,
Repertory Grid Technique,
Turkey

Research Article

To Cited : İkikat Tümer E 2018. Lise ve Dengi Okullardaki Öğrencilerin Fast Food Tüketim Kararları. KSÜ Tarim ve Doğa Derg 21(1):1-6, DOI:10.18016/ksudobil.348267.

\section{Gİiș}

Birçok ülkede ekonomik gelişme ile birlikte gıda tüketim alışkanlıkları da değişmiş ve ev dışı gıda tüketimi artmıştır. Türkiye'de ev dışı gıda harcamasının toplam gıda harcaması içindeki payı her geçen gün artmaktadır (Akbay and Boz 2005). Kadınların iş hayatına girmesi, zamanının büyük bir bölümünü işte geçirmesi, aile gelirinin artması (Jekanowski 1997), büyük şehirlerdeki ulaşım problemi, fast food restoranların sayısındaki hızlı artış ve bu restoranların evlere servis yapması gibi faktörler nedeniyle kısa sürede hazırlanan ya da hazır tüketilen yiyecekler günümüz toplumlarında önem kazanmaktadır. Ailelerin beslenme ve yemek pişirme alışkanlıkları, yemek malzemeleri almaya ve yemek hazırlamaya ayırdıkları zaman, hazır yiyecekleri tüketme miktarları zaman içerisinde önemli ölçüde değişiklik göstermiştir (Şanlıer and Yabancı 2003). Bu durum aileleri kısa sürede hazırlanan ve hızlı bir şekilde servis edilen yiyeceklere (Fast food) yöneltmektedir.

Türkiye'de en çok tüketilen fast-food yiyecek içecekler arasında simit, tost, döner, lahmacun, pide, hamburger çeşitleri, soğuk sandviçler, pizza, kızarmış 
patates, kızarmış parça tavuk, balık-ekmek, kumpir, kokoreç, kolalı içecekler, çay, kahve vb. yer almaktadır (Paksoy ve Akdemir 1998, Özçelik et al 2007, Erdem et al 2011). Hazır yiyecekler yol üstlerindeki büfelerde, seyyar arabalarda ya da lüks fast food restoranlarında satılmaktadır. Besin değeri düşük, kalori oranı ve doymamış yağ oranı yüksek oluşu, damar tıkanıklığı ve obezite gibi hastalıklara yakalanma riskini artıran bu gidaları tüketme sağlıksız beslenme şekli olarak bilinmektedir (Anonim 2013a).

Anne karnında başlayan ve hayatın sonuna kadar devam eden "beslenme; sağllğı korumak, geliştirmek ve yaşam kalitesini yükseltmek için vücudun gereksinimi olan besin öğelerini yeterli miktarlarda ve uygun zamanlarda almak için bilinçli yapılması gereken bir eylemdir" (Anonim 2013b). 21. yüzyılda çocuklar boş zamanlarını bahçelerde veya sokak aralarında oynayarak geçirmek yerine, gelişen teknolojinin, artan gelir ve değişen sosyal yapının da etkisiyle televizyon ve bilgisayar başında geçirmektedirler. $\mathrm{Bu}$ durum beslenme ve spor alışkanlıklarındaki değişimle birlikte obeziteyi de beraberinde getirmektedir (Öztora 2005). Fast food gıda tüketimi çocukluk çağında başlamakla birlikte (Hofferth and Curtin 2005) yaşam boyu süren kronik bir enerji metabolizması bozukluğu olup, vücuda ihtiyacı olandan fazla enerji alınmasıdır (Lin et al., 1999; Binkley et al., 2000; French et al., 2000, 2001; Paeratakul et al., 2003; Bowman et al., 2004; Bowman and Vinyard, 2004; Befort et al., 2006).

Okul öncesi yaşlarda şişman çocukların \%26-41'inin, okul çağında şişman olanların ise yaklaşı yarısının (\%42-63) erişkin yaşta şişman kalmaya devam ettiği (Anonim, 2013c) ve obezitenin çocuk ile adolesanların \%25-30'unu etkileyen önemli bir beslenme problemi olduğu tespit edilmiştir (Gürel and İnan 2001, Strock et al 2005). Türkiye Diyabet, Hipertansiyon, Obezite ve Endokrinolojik Hastalıklar Prevalans Çalışması-II (TURDEP-II) sonuçlarına göre Türkiye'de obezite sıklığı \%32 olarak bulunmuştur (Anonim, 2013d). Bunun yanı sıra çocuk yaşlarda tüketilmeye başlanan ve erişkin yaşlarda ise hayatın bir parçası olan fast food tüketimi ile kilo artı̧̧ı arasında ilişki olduğu tespit edilmiştir (Binkley et al., 2000; French et al., 2000; Bowman and Vinyard, 2004). Türkiye'de yapılan bir çalışmada ise çocukların tercihi, fast food tüketim sıklığını artıran önemli bir faktör olarak belirlenmiştir (Akbay and Jones, 2005; Akbay et al, 2007, ).

$\mathrm{Bu}$ çalışmada lise ve dengi okullarda eğitim gören öğrencilerin fast food tüketim karaları ve bu kararlarında etkili olan faktörlerin ortaya konulması amaçlanmıştır.

\section{MATERYAL ve METOT}

Çalışmanın verileri Erzurum İli Aziziye, Palandöken ve Yakutiye İlçelerinde 11 lise ve dengi okullarda kayıtlı olan öğrencilerle yüz yüze yapılan anketlerden elde edilmiştir. Araştırmada görüşülecek öğrenci sayısı Oransal Örnekleme Yöntemi ile 126 kişi tespit edilmiştir (Newbold 1995, Miran 2010).

$$
n=\frac{N^{*} p^{*}(1-p)}{(N-1) * \sigma_{p}^{2}+p^{*}(1-p)}=126
$$

Formülde; n:Örnek büyüklüğü, N:Popülasyondaki öğrenci sayısı, o2p:Oranın varyansı, p:Öğrenci sayısının popülasyondaki oranını göstermektedir. Toplam 126 anket okullara ve her okuldaki sınıfların $(9, \quad 10, \quad 11, \quad 12)$ öğrenci sayılarına oranlanarak dağıtılmıştır.

Dünya Sağlık Örgütü tarafından yapılan hesaplamalar sonucunda vücut kitle indeks (BMI) sinıflaması Çizelge 1.'de verilmiştir. BMI, vücut ağırlığının (kg) boy uzunluğunun (m) karesine bölünmesi ile hesaplanmaktadır.

Repertuar çizelgesi tekniği (RGT), olaylar ve durumlar karşısında ya da belirlenen bir konu hakkında bireylerin kişisel kurgularının ortaya çıkarılması ve kurgu sisteminin nasıl çalıştığını belirlemek için kullanılan bir yöntemdir (Kelly, 1955). Bu analizde mutlak doğru veya nesnel gerçeklik yoktur ve olaylar yalnızca bireylerin kurgularında yola çıkarak yaptıkları yorumlarıyla anlam kazanmaktadır. Her bir kurgu, büyük-küçük, yakın-uzak, iyi-kötü gibi bir kutuptan diğer zit kutuba olacak şekilde oluşturulan ölçümle birlikte düz bir çizgi halinde canlandırılabilir. (Ilbery ve Hornby, 1983). Bireylerin olaylar karşısında karar vermesinde RGT kullanılan bir tekniktir. RGT analizinde öncelikle RGT elementleri olarak konu ile ilgili özel fikir, kavram ya da nesneler oluşturulur (Latta and Swigger, 1992).

Çizelge 1. Dünya Sağlık Örgütüne göre vücut kitle indeksi (BMI) siniflaması

\begin{tabular}{ll}
\hline $\begin{array}{l}\text { BMI değerleri } \\
\left(\mathrm{kg} / \mathrm{m}^{2}\right)\end{array}$ & \multicolumn{1}{c}{ Sınıflama } \\
\hline$<18.5$ & Zayıf \\
$18.5-24.9$ & Normal \\
$25.0-29.9$ & Toplu, hafif şişman, fazla kilolu \\
$30.0-39.9$ & Şişman (Obez) \\
$\geq 40.0$ & Aşııı şişman \\
\hline
\end{tabular}

$\mathrm{Bu}$ çalışmada lise ve dengi okullarda hazır içecek, yiyecek ve hazır sıcak yiyecek değişkenleri dikkate alınarak kurgu hazırlanmıştır. Farklı öğrenci gruplarının fast food gida tüketimlerine ilişkin farklı tutum ve algılara sahip olup olmadıları belirlenecektir.

\section{BULGULAR VE TARTIŞMA}

Ankete katılan lise ve dengi okullarda okuyan öğrenciler ortalama 15.89 yaşındadırlar. Bu öğrenciler ortalama $165.90 \mathrm{~cm}$ boyunda ve $56.22 \mathrm{~kg}$ ağırlığında olup BMI 20.39 olarak tespit edilmiştir. Dünya Sağlık Örgütü verileri ile kıyaslandığında (Anonim 2013e) ögrrencilerin normal kiloda (BMI değeri 18.5-24.9 arasında) (Çizelge 1) olduklarını söylemek 
mümkündür (Çizelge 2).

Öğrencilerin ortalama 3.36 kardeşleri bulunmaktadır. Ankete katılanlar ayda ders dışı ortalama 1.39 adet kitap okumakta, ortalama $1.28 \mathrm{kez}$ sinemaya gitmekte, günde ortalama 1.78 saat TV izlemekte ve günde ortalama 1.33 saat internet kullanmaktadırlar. Ayrıca öğrenciler haftada ortalama $5.18 \mathrm{kez}$ aileleriyle birlikte akşam yemeği yemektedirler (Çizelge 2).

Çizelge 2. Öğrencilerin sosyo-demografik özellikleri

\begin{tabular}{lcccc} 
& Minimum & Maksimum & Ortalama & Std. sapma \\
\hline Yaş & 14 & 19 & 15.89 & 1.234 \\
Boy & 143 & 185 & 165.90 & 8.714 \\
Kilo & 36 & 79 & 56.22 & 8.163 \\
BMI & 16.53 & 25.39 & 20.39 & 2.291 \\
Seviye Belirleme Sınavı (SBS) not ortalaması & 173.7 & 487.4 & 368.616 & 76.615 \\
Dershaneye gitme (yıl) & 0 & 4 & 1.14 & 1.120 \\
Kardeş sayısı & 1 & 9 & 3.36 & 1.422 \\
Ayda ders dışı okunan kitap sayısı & 0 & 3 & 1.39 & 0.839 \\
Aylık sinemaya gitme sayısı & 0 & 4 & 1.28 & 1.177 \\
TV izleme süresi (saat/gün) & 0 & 5 & 1.78 & 1.182 \\
Internet kullanma süresi (saat/gün) & 0 & 7 & 1.33 & 1.414 \\
Aile ile birlikte aksam yemeği (kez/hafta) & 0 & 7 & 5.18 & 2.544 \\
Haftalık hazır içecek tüketim sayısı & 0 & 14 & 3.90 & 3.064 \\
Haftalık hazır yiyecek tüketim sayısı & 0 & 15 & 4.71 & 3.080 \\
Haftalık sıcak yiyecek tüketim sayısı & 0 & 15 & 2.63 & 2.560 \\
\hline
\end{tabular}

Ankete katılan öğrencilerin \%49'u bay olup, \%74'ünün kendine ait bir odası bulunmaktadır. Öğrencilerin \%14'ünün annesi çalışmakta ve \%70'inin evlerinde bilgisayar bulunmaktadır. Düzenli olarak spor yapan ögrrencilerin oranı \%43 ve sigara kullananların oranı ise \%13 olarak hesaplanmıştır (Çizelge 3).

Ankete katılan öğrencilerin \%48.4'ünün ailesi 10001999 TL aylık gelire sahiptir. Öğrencilerin \%4'ü haftalık 9 TL ve daha az, \%37.2'si ise 21-30 TL harçlık almaktadırlar. Güne zinde bir şekilde başlamak ve gün içinde bulunduğumuz faaliyetlerde anlama, algılama, anımsama ve verimli bir şekilde çalışma üzerinde kahvaltının çok önemli etkileri vardır. Kahvaltı günün en önemli öğünü olmasına karşın aynı zamanda günün en çok atlanan öğünü haline gelmiştir. Çalışmada öğrencilerin \%53.2'sinin her sabah evlerinde kahvaltı yaptıkları, \%7.1'inin ise evde hiç kahvaltı yapmadıkları belirlenmiştir (Çizelge 4).

Cizelge 3. Öğrencilerin özellikleri

\begin{tabular}{lcc}
\hline & $\%$ & $\begin{array}{c}\text { Std. } \\
\text { sapma }\end{array}$ \\
\hline Cinsiyet (bayan:0, bay:1) & 0.49 & 0.502 \\
Kendine ait oda (yok:0, Var:1) & 0.74 & 0.441 \\
$\begin{array}{l}\text { Annenin çalışma durumu } \\
\text { (Calişmiyor:0, Çalışıor:1) }\end{array}$ & 0.14 & 0.351 \\
$\begin{array}{l}\text { Evde bilgisayar olma durumu } \\
\text { Spor (Düzenli olarak }\end{array}$ & 0.70 & 0.461 \\
$\begin{array}{l}\text { yapiyorsa:1, Diğer:0) } \\
\begin{array}{l}\text { Sigara kullanma (Sigara } \\
\text { kullaniyorsa:1, Diğer:0) }\end{array}\end{array}$ & 0.43 & 0.497 \\
\hline
\end{tabular}

Çocuk ve adölesanlarda ayaküstü beslenme (Ebbeling et al 2004), tatlandırılmış içeceklerin tüketimi (Ludwing et al 2001; Bachman et al, 2006) obeziteye sebep olmaktadır. Erzurum'da öğrenciler haftalık ortalama 3.90 adet hazır içecek, 4.71 adet hazır yiyecek ve 2.63 adet hazır sicak yiyecek tüketmektedirler (Çizelge 2).
Çizelge 4. Öğrencilerin özellikleri

\begin{tabular}{llll}
\hline & & Frekans & $\%$ \\
\hline & $<1000$ & 28 & 22.3 \\
Gelir (TL/ay) & $1000-1999$ & 61 & 48.4 \\
& $2000-4999$ & 26 & 20.6 \\
& $5000+$ & 11 & 8.7 \\
& Total & 126 & 100.0 \\
\hline & $0-9$ & 5 & 4.0 \\
& 1020 & 38 & 30.2 \\
Harçlık (TL/hafta) & $21-30$ & 47 & 37.2 \\
& $31-40$ & 20 & 15.9 \\
& $41+$ & 16 & 12.7 \\
& Total & 126 & 100.0 \\
\hline \multirow{3}{*}{ Evde kahvaltı } & Hiç & 9 & 7.1 \\
yapma sıklığ1 & Bazen & 50 & 39.7 \\
& Her zaman & 67 & 53.2 \\
& Total & 126 & 100.0 \\
\hline
\end{tabular}

$\mathrm{Bu}$ çalışmada, öğrencilere tükettikleri gıdalarla ilgili olarak gıdaların fiyatı, lezzeti, sağlıklı olması ve kısa sürede hazırlanması olmak üzere toplam dört kriter sunulmuştur. $\mathrm{Bu}$ kriterlere verdikleri öneme göre değer vermeleri istenmiştir. Öğrencilerin bu kriterler arasında tükettikleri gıdaların lezzetli olmasına en fazla önemi verdikleri tespit edilmiştir. Daha sonra sırasıyla tükettikleri gidaların sağlıklı olması, hazırlama süresi ve fiyatına önem verdikleri belirlenmiştir (Çizelge 5). 
Çizelge 5. Öğrencilerin tükettikleri gidalarda dikkat ettikleri özelliklerin ağırlıkları

\begin{tabular}{lr}
\hline & Ortalama \\
\hline Fiyat & 3.2143 \\
Hazırlama süresi & 3.7302 \\
Sağllk & 4.1270 \\
Lezzet & 4.4841 \\
\hline
\end{tabular}

Friedman testi $p<0.01$ için anlamlıdır.

Kendall's $W=0.071$

Friedman testi, birbiri ile ilişkili iki ya da daha fazla değişkene ait dağılımların karşılaştırılarak dağılımlar arasında anlamlı bir fark olup olmadığını test etmek amacı ile kullanılır. Öğrencilerin tükettikleri gıdalarda dikkat ettikleri özellikler arasında fark olup olmadığı Friedman testi ile analiz edilmiştir (Çizelge $5)$. Analiz sonucunda $(p<0.01)$ öğrencilerin tükettikleri gıdalarda dikkat ettikleri özellikler arasında fark olduğu belirlenmiştir.

Öğrencilerin, tükettikleri gıdalar arasında en fazla önemi hazır sıcak yiyeceklere verdikleri belirlenmiştir. Daha sonra sırasıyla hazır paketlenmiş yiyecek ve hazır içeceklere önem verdikleri tespit edilmiştir (Çizelge 6).

Çizelge 6. Öğrencilerin tükettikleri gıda çeşitlerinin ağırlıkları

\begin{tabular}{lc}
\hline & Ortalama \\
\hline Hazır içecek & 53.9048 \\
Hazır paketlenmiş yiyecek & 60.4762 \\
Hazır sıcak yiyecek & 60.5714 \\
\hline
\end{tabular}

Friedman testi $p<0.01$ için anlamlıdır.

Kendall's $W=0.199$

Öğrencilerin tükettikleri gidalar arasında fark olup olmadığı analiz edilmiş ve analiz sonucunda $(p<0.01)$ öğrencilerin tükettikleri gıda çeşitleri arasında fark olduğu belirlenmiştir.

Öğrenciler sınıflarına bakılmaksızın en fazla önemi fast food gidaların lezzetli olmasına, en az önemi ise fiyatına vermektedirler. Zayıf ve normal öğrenciler fast food gidaların fiyatına, hafif şişman öğrenciler hazırlama süresine en az önemi vermektedirler (Çizelge 7).

Vücut kitle indeksine göre tüm öğrenciler en fazla önemi fast food gidaların lezzetli olmasina vermektedirler. Zayıf ve normal öğrenciler fast food gıdaların fiyatına, hafif şişman öğrenciler hazırlama süresine en az önemi vermektedirler (Çizelge 8).

Evlerinde düzenli olarak yemek pişen öğrenciler en fazla önemi fast food gidaların lezzetli olmasina, en az önemi ise fiyatına vermektedirler. Evlerinde düzenli olarak yemek pişmeyen öğrenciler ise en fazla önemi fast food gidaların lezzetli ve sağlıklı olmasına, en az önemi ise fiyatına ve hazırlama süresine vermektedirler (Çizelge 9).

Ailelerinden harçlık almayan öğrenciler en fazla önemi fast food gidaların sağlıklı olmasına, en az önemi ise gıdaların hazırlama süresine vermektedirler. Ailelerinden harçlık alan öğrenciler en fazla önemi fast food gidaların lezzetli olmasina, en az önemi ise fiyatına vermektedirler (Çizelge 10).

Çizelge 7. Öğrencilerin sinıflara göre tükettikleri gıdalarda dikkat ettikleri özelliklerin ağırlıkları

\begin{tabular}{lcccc}
\hline Sinıf & Sağlık & Fiyat & Lezzet & $\begin{array}{c}\text { Hazırlama } \\
\text { süresi }\end{array}$ \\
\hline 9 & 4.36 & 3.29 & 4.58 & 3.67 \\
10 & 3.71 & 3.00 & 4.35 & 3.58 \\
11 & 4.32 & 3.28 & 4.48 & 3.84 \\
12 & 4.04 & 3.28 & 4.48 & 3.92 \\
\hline
\end{tabular}

Çizelge 8. Öğrencilerin BMI göre tükettikleri gidalarda dikkat ettikleri özelliklerin ağırlıkları

\begin{tabular}{lcccc}
\hline & Sağllk & Fiyat & Lezzet & $\begin{array}{c}\text { Hazırlama } \\
\text { süresi }\end{array}$ \\
\hline Zayıf & 4.10 & 3.10 & 4.69 & 3.83 \\
Normal & 4.14 & 3.23 & 4.40 & 3.72 \\
Hafif şişman & 4.00 & 3.75 & 5.00 & 3.25 \\
\hline
\end{tabular}

Çizelge 9. Öğrencilerin evde düzenli olarak yemek pişme durumuna göre tükettikleri gidalarda dikkat ettikleri özelliklerin ağırlıkları

\begin{tabular}{lcccc}
\hline & Sağlık & Fiyat & Lezzet & $\begin{array}{c}\text { Hazırlama } \\
\text { süresi }\end{array}$ \\
\hline Hayır & 4.25 & 3.38 & 4.25 & 3.38 \\
Evet & 4.12 & 3.20 & 4.50 & 3.75 \\
\hline
\end{tabular}

Çizelge 10. Öğrencilerin aileden aldıkları harçlık miktarına göre tükettikleri gıdalarda dikkat ettikleri özelliklerin ağırlıkları

\begin{tabular}{lcccc}
\hline & Sağlık & Fiyat & Lezzet & $\begin{array}{c}\text { Hazırlama } \\
\text { süresi }\end{array}$ \\
\hline Yok & 4.60 & 3.80 & 4.40 & 2.40 \\
1-10 TL & 4.16 & 3.26 & 4.21 & 3.92 \\
11-20 TL & 4.28 & 3.45 & 4.51 & 3.74 \\
21- 30 TL & 4.00 & 2.65 & 4.95 & 3.90 \\
31 TL + & 3.63 & 2.94 & 4.50 & 3.44 \\
\hline
\end{tabular}

\section{SONUÇ ve ÖNERİLER}

Türkiye'de 1980'li yıllardan sonra fast food tüketim alışkanlığ 1 ve fast food endüstrisinin zaman içerisinde hızla gelişerek çeşitliliğini arttırması, bu restoranların evlere servis yapması, hanehalkı gelirinin artması, kadınların iş hayatına atılması ve çevresel faktörler nedeniyle hızla artı̧̧ göstermiştir.

Çalışmada lise ve dengi okullarda eğitim gören öğrencilerin fast food tüketim amaçları ve bu amaçlarını belirlemede etkili olan faktörlerin ortaya konulması için Repertuar çizelgesi tekniği yapılmıştır. Analiz sonucunda öğrenciler gıdaların fiyatı, lezzeti, sağlıklı olması ve kısa sürede hazırlanması kriterleri 
arasından tükettikleri gidaların lezzetli olmasına en fazla önemi vermektedirler. Daha sonra sirasiyla tükettikleri gıdaların sağlıklı olması, hazırlama süresi ve fiyatına önem verdikleri belirlenmiştir.

Çocuklarının fast food tüketimini azaltmak isteyen aileler onların evde kahvaltı yapmalarına daha fazla özen gösterebilirler. Böylelikle evden kahvaltı yaparak çıkan öğrencilerin dışarıda bir şeyler atıştırma ihtiyacı azalacaktır. Bunun yanı sıra aileler pizza, lahmacun gibi evlere sicak servis edilen yiyeceklerin tüketilme sıklığını azaltabilirler. Bununla birlikte mevsimine göre taze sıkılmış meyve suyu (elma, havuç, portakal, vişne gibi) ve limonata gibi evde hazırlanan içecekler ile çocukların haftalık hazır içecek tüketimi azaltılabilir. Anneler lezzetli, az yağlı, düşük kalorili yemekler yapmaya özen gösterebilirler. Özellikle ailelere, okul yemekhane yöneticilerine sağlıklı ve lezzetli yemek yapımı konusunda seminerler, kurslar verilebilir. $\mathrm{Bu}$ konuda halk eğitim merkezlerinden destek alınabilir. Ayrıca toplumda yeterli ve dengeli beslenme, fiziksel aktivite alışkanlığının kazandırılması ile obezite ve oluşturduğu sağlık riskleri konusunda farkındalık oluşturulabilir.

Her geçen gün fast food gida tercih eden öğrencilerin oranının artması obezite riskini de beraberinde getirmektedir. Gelecek neslin hem sağlıklı olması hem de obezite ile mücadele masraflarının azaltılması için okullarda fast food tipi gıdaların satışı kontrol altına alınabilir.

Bu çalışmanın sonuçlarıyla aileler, okul yöneticileri ve bu konu ile ilgilenen kurum ve kuruluşlar öğrencilerin fast food (hazır içecek, yiyecek ve hazır sıcak yiyecek) tüketimini azaltıcı, sağlıklı besin tüketimini artırıcı tedbirler alabilirler. Aileler, öğretmenler ve Milli Eğitim Kurumlarında öğrenciler ile ilgilenen birim çalışanları hep birlikte öğrencilerin sağlıklı yaşamasına engel olan obezite ile mücadele edebilirler. Gerekirse bu konuda yerel yönetimden destek alınarak "obeziteye hayır" kampanyaları başlatılabilir. Ayrıca Sağlık Bakanlığı, Milli Eğitim Bakanlığı, üniversite ve yerel yönetimin işbirliği içinde olduğu, sağlıklı yaşam için beslenme, spor ve obezitenin zararları konusunda toplum bilinci oluşturma amacını taşıyan projeler yürütülebilir.

\section{KAYNAKLAR}

Akbay C, Boz I 2005. Ekonomic Analysis of Food at Home and Food Away From Home Consumption and Consumer Behavior in Kahramanmaras. KSU Journal of Science and Engineering, Volume:8(1)pp:122-131.

Akbay C, Jones E 2005. Food Consumption behavior of socioeconomic groups for private labels and national brands. Food Quality and Preference. 16:621-631.

Akbay C, Tiryaki GY, Gul A 2007. Consumer Characteristics Influencing Fast Food Consumption in Turkey. Food Control, 18, 904-913.
Anonim 2013a. Fast Food. http://tr.wikipedia.org/wiki/Fast_food (Erişim tarihi: 30.05.2013).

Anonim 2013b. Türkiye'ye Özgü Beslenme Rehberi, Yeterli ve Dengeli Beslenme. http://www.danoneenstitusu.org.tr/pdf/turkiyey e_ozel_beslenme_rehberi.pdf

(Erişim tarihi: 30.05.2013).

Anonim 2013c. Çocukluk ve Ergenlik Döneminde Beslenme. http://www.beslenme.saglik.gov.tr/ content/files/yayinlar/kitaplar/obezite_bilgi_seri si/D2.pdf (Erişim tarihi: 30.05.2013).

Anonim 2013d. TURDEP II Sonuçlarının Özeti. http://www.istanbul.edu.tr/itf/attachments/ 021_turdep.2.sonuclarinin.aciklamasi.pdf. (Erişim tarihi: 30.05.2013).

Anonim 2013e. Physical status: the use an interpretation of anthropometry: report of a WHO expert committee. World Health Organisation, Tech Rep Ser 854, Geneva,pp 1-452.

Bachman CM, Baranowski T, Nicklas TA 2006. Is there an association between sweetened beverages and adiposity? Nutrition Reviews.64:4:153-174.

Befort C, Kaur H, Nollen N, Sullivan, DK, Nazir N, Choi WS 2006. Fruit, Vegetable, and Fat Intake Among Non-Hispanic Black And Non-Hispanic White Adolescents: Associations With home availability and Food Consumption Settings. Journal of the American Dietetic Association 106 (3), 367-373.

Bowman SA, Gortmaker SL, Ebbeling CB, Pereira MA, Ludwig DS 2004. Effects of Fast-food Consumption on Energy intake and Diet Quality among Children in a National Household Survey. Pediatrics 113 (1 Pt 1), 112-118.

Bowman SA, Vinyard BT 2004. Fast Food Consumption of U.S. Adults: Impact on Energy and Nutrient Intakes and Overweight Status. Journal of the American College of Nutrition 23 (2), 163-168.

Ebbeling CB, Sinclair KB, Pereira MA, Garcia-Lago E, Feldman HA, Ludwig DS 2004. Compensation for Energy Intake from Fast Food among Overweight and Lean Adolescents. Jama, 291(23) pp:2828-2833.

Erdem TN, Uzakgider N, Aksoy M 2011. Fast-Food Tüketim Tarzının Aile Fonksiyonlarına etkisi: Eskişehir Örneği. Türkiye Bilimsel ve Teknolojik Araştırma Kurumu.

French SA, Harnack L, Jeffery RW 2000. Fast food restaurant use among women in the Pound of Prevention study: dietary, behavioral and demographic correlates. International Journal of Obesity 24 (10), 1353-1359.

Gurel S, İnan G 2001. Çocukluk Cağı Obezitesi Tanı Yöntemleri, Prevalansı ve Etyolojisi. ADU Tip Fakültesi Dergisi, Volume:2(3), pp:39-46. 
Hofferth SL, Curtin S 2005. Poverty, Food Programs, and Childhood Obesity. Journal of Policy analysis and Management, Volume 24, Issue 4, pp:703-726.

Ilbery BW, Hornby R 1983. Repertory Grids and Agricultural Decision-Making: A Mid-Warwickshire Case Study, Human Geography, 65(2), 77-84.

Jekanowski M, Binkley JK, Eales J 1997. The impact of demographics, market characteristics, and prices on the consumption of food-away-from home. Western agricultural economics association annual meeting, July 13-16, Reno/Sparks, Nevada.

Kelly GA 1955. The Psychology of Personal Constructs, Norton, New York, NY.

Latta GF, Swigger K 1992. Validation of the Repertory Grid for Use in Modeling knowledge, Journal of the American Society for Information Science, Vol. 43(2), pp: 115-129.

Lin BH, Guthrie J, Frazão E 1999. Quality of children's diets at and away from home: 1994-96. Food Review 22 (1), 2-10.

Ludwig DS, Peterson KE, Gortmaker SL 2001. Relation between consumption of sugar-sweetened drinks and childhood obesity: A prospective, observational analysis. Lancet, 357:505-508.

Miran B 2010. Temel İstatistik. Ege Üniversitesi Basımevi, Bornova, İzmir.

Newbold P (1995). Statistics for Business \& Economics, Fourth Edition, 1995, Prentice-Hall.
Özçelik AÖ, Akan LS, Sürücüoğlu MS 2007. An evaluation of fast food preferences acording to geender. Humanity Social Sciences Journal, 2 (1), 4350.

Öztora S 2005. İlköğretim Çağındaki Çocuklarda Obezite Prevalansının Belirlenmesi ve Risk Faktörlerinin Araştırılması, Uzmanlık Tezi, Sağlık Bakanlığı Bakırköy Dr. Sadi Konuk Eğitim ve Araştırma Hastanesi Dr. Sami Hatipoğlu Çocuk Sağlığı ve Hastalıkları Kliniği Şefi Ve Aile Hekimliği Koordinatoru

Paeratakul S, Ferdinand DP, Champagne CM, Ryan DH, Bray GA 2003. Fast-food consumption among US adults and children: dietary and nutrient intake profile. Journal of the American Dietetic Association 103 (10), 1332- 1338.

Paksoy M, Akdemir Ş 1998. Kahramanmaraş İli Kentsel Alanda Hayvansal Gıda Maddeleri Tüketimi ve Gelir Harcama Esneklikleri, Kahramanmaraş Sütçü İmam Üniversitesi Fen ve Mühendislik Dergisi, 2(1), 80-90.

Strock, G.A, Cottrell, E.R, Abang, A.E, Buschbacher, R.M., Hannon, T.S. 2005. Childhood Obesity: A Simple Equation with Complex Variables. J Long Term Eff Med Implants. Volume:15(1), pp:15-32.

Şanlıer N, Yabancı N 2003. Okul Öncesi Dönemi Çocukların Fast Food Tüketim Alışkanlıkları ve Annelerin Bu Tür Beslenmeye Karşı Yaklaşımları Standart Ekonomik ve Teknik Dergi, Yıl: 42, Sayı: 497: 59-64. 